\title{
Comparative growth forms of dryland forage legumes
}

\author{
R.G. THOMAS \\ AgResearch Grasslands, Private Bag 11008, Palmerston North
}

\begin{abstract}
Basic forage legume morphology and development are described with reference to white, red, subterranean and caucasian clovers, lotus and lucerne, with emphasis on characteristics that relate to persistence in dryland environments, including crown formation, contractile tap roots and rhizomes.

The range of structural variation is considered in detail by comparing development of plants with two extreme growth forms, i.e. white clover, which has branching horizontal growth and nodal roots, and lucerne and caucasian clover, which have vertical growth, permanent crowns and deep tap roots. Emphasis is placed on carbon allocation strategies during establishment and the inevitable compromise between shoot and root growth, which results in slow seedling establishment of the tap-rooted species, and on the effect of nodal roots as competitive sinks for carbon, which affect tap root development and longevity in white clover. The influence of storage tissues and the number of viable buds on regrowth following drought, overwintering and grazing is discussed together with the impact of variations in flowering shoot formation.
\end{abstract}

All existing growth forms are seen as having evolved as compromise solutions to the problem of combining maximum growth rates with optimum drought tolerance. The possibility, or otherwise, of being able to combine rapid establishment, involving maximised leaf production, with development of a persistent deeply penetrating tap root is considered in light of present understanding.

Key words: carbon allocation, dryland environment, forage legume, morphology, nodal roots, persistence, root:shoot ratio, seedling establishment, tap roots

\section{Introduction}

Development and growth characteristics of forage legumes and their relationship to competition and persistence have been well reviewed previously (e.g. Forde et al. 1989; Sheaffer 1989; Sheath \& Hay 1989). The aim of the present paper is to provide a deeper understanding of the relationship between their growth forms and their establishment and persistence in dryland pasture environments. The typical forage legumes grown in New Zealand have relatively soft mesomorphic leaves, which lose water readily through both upper and lower surfaces, and non-woody stems. They are not well adapted morphologically to survive extreme drought conditions and do so either by avoiding drought altogether (in the case of annual plants such as subterranean clover) or, in perennial forms, by resisting it, largely by the development of deep water-seeking tap roots. Emphasis here is placed on this perennial category.

\section{Growth and development}

Plant forms are the products of their growth and development. These can be divided conveniently into four phases: early seedling development, development of the mature plant form, flowering, and post-flowering.

\section{Early seedling development}

The pattern of morphological development immediately after seed germination is very similar in all pasture legumes (Figure 1). Germination leads to the emergence of a seedling (seminal) root and two cotyledons. A terminal shoot bud is located between the cotyledons and two axillary cotyledonary buds sit either side of this at the bases of the cotyledons. The terminal bud immediately grows to produce leaves attached to a primary stem. Each leaf subtends an axillary bud. In some plants, such as lotus, several additional cotyledonary buds regularly form in the axils of the cotyledons; in others, such as white clover, seedlings occasionally do so (M.J.M. Hay pers. comm.).

Once a seedling's seminal root is established, its upper region, together with the hypocotylar region of its stem, contracts, pulling the cotyledonary buds and lowermost axillary buds below the soil surface. The degree of contraction varies from about $5 \mathrm{~mm}$ in white clover and $10 \mathrm{~mm}$ in Lotus corniculatus and red clover to as much as $20 \mathrm{~mm}$ in lucerne (Nelson \& Mosr 1995). 


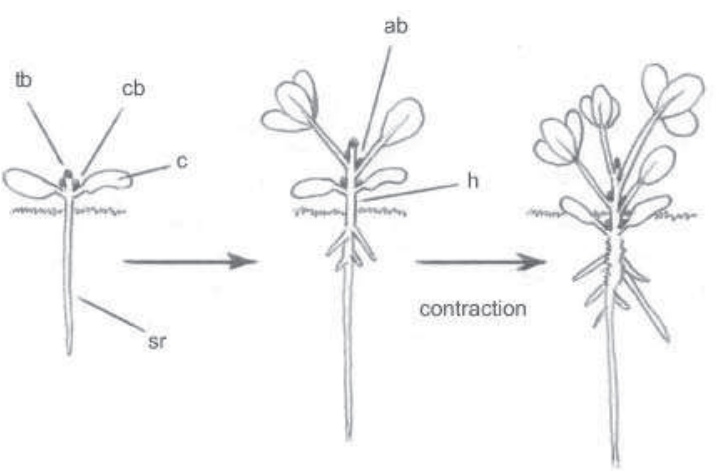

Figure 1 Diagram showing early development of a generalised forage legume seedling. $\mathrm{tb}=$ terminal bud, $\mathrm{ab}=$ axillary bud, $\mathrm{c}=$ cotyledon, $\mathrm{cb}=$ cotyledonary bud, $\mathrm{h}=$ hypocotyl, $\mathrm{sr}=$ seminal root.

\section{Establishment of the mature plant form}

\section{Branches}

Continued development of the seedling in all cases leads to the formation of an initial crown of branches growing atop a central tap root. The first of these grow from the cotyledonary buds and from the lowermost axillary buds on the primary stem and have a structure similar to that shown in Figure 2. They have alternately arranged leaves each of which subtends an axillary bud enclosed to various degrees by a pair of stipules formed at the leaf base. Not all seedling buds develop early into elongating branches, however. Instead, some remain inactive, providing a pool of buds that retain the potential to develop into branches subsequently.

Further development varies greatly. In white, red and subterranean clover, the long petioles of the leaves

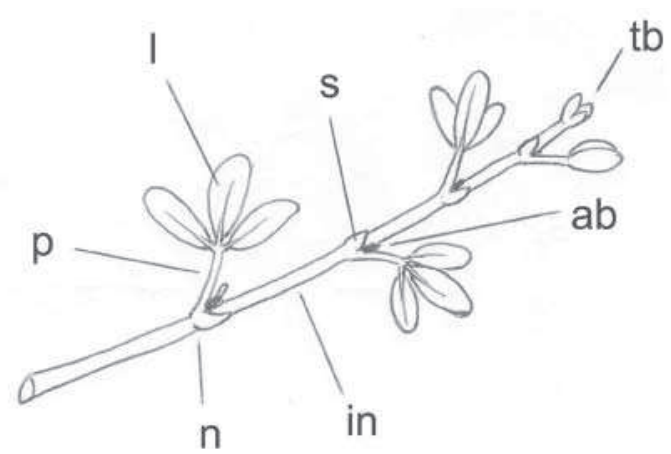

Figure 2 Diagram of a generalised forage legume branch. tb $=$ terminal bud, $\mathrm{p}=$ petiole, $\mathrm{I}=$ leaflet lamina, $\mathrm{s}=$ stipule, $\mathrm{ab}=$ axillary bud, $\mathrm{n}=$ node, in = internode. raise them well above ground level. In these, the primary shoot elongates very little and stops growing after producing about 10 leaves (Figure 3D,E,F), giving their seedlings an initial rosette habit. In others, such as lucerne, the leaves have short petioles and the primary shoot continues to elongate (Figure 3B,C), thereby raising the leaf blades above ground level and creating an initial caulescent habit. As the plants mature, non-flowering branches either elongate strongly (horizontally to form stolons in white and subterranean clovers; vertically in lotus and lucerne) or remain relatively short and slightly ascending in red and caucasian clovers. New leaves are produced at the extreme apex of each branch. Each terminal bud contains six to eight young leaves at a range of developmental stages leading up to their emergence from their initial formation as leaf primordia. In white clover, many of those buds that do not elongate into branches grow out slowly into short shoots (Thomas et al. 2002). In some species, such as caucasian clover, buds that are pulled below the soil surface by contraction of the seedling axis and tap root grow into underground rhizomes.

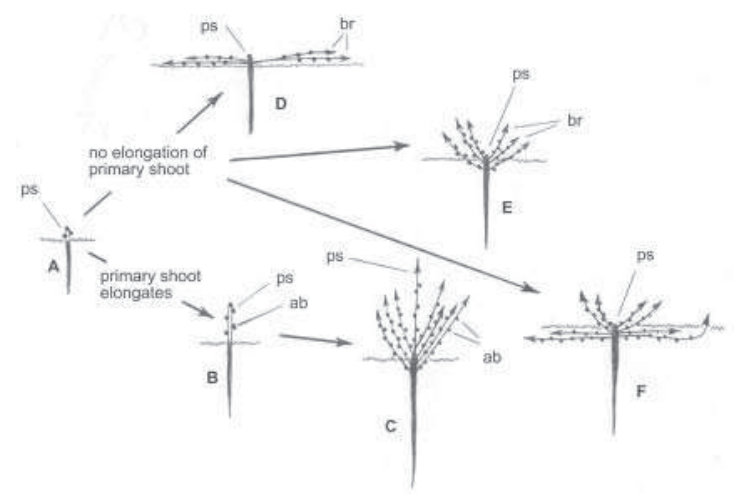

Figure 3 Diagrammatic representation of the development of different forage legume morphologies. ps = primary shoot, $a b=$ axillary buds, $b r=$ branches. $A=$ generalised seedling; $B, C=$ lucerne; $D=$ white and subterranean clover; $\mathrm{E}=$ lotus and red clover; $\mathrm{F}=$ caucasian clover.

\section{Roots}

Typically, in many pasture legumes, each node on a vegetative stem is capable of forming one or two roots under moist conditions. This is particularly the case in white clover, but also occurs frequently at nodes maintained in moist conditions near or below ground level in red and caucasian clovers and in lotus. Nodal roots most often develop into fibrous root 
systems rather than into tap roots. In white clover, they occur abundantly along the length of horizontal stems. In red and caucasian clovers, however, where they develop close to the seminal tap root, a few develop into secondary tap roots, thereby giving rise to an augmented crown consisting of a cluster of several tap roots, each of which is surmounted by its own sub-crown of buds and branches (Figure 4).

In all the perennial species under discussion, the upper region of each tap root continues to contract throughout its life, thereby constantly drawing the lowermost shoot buds below the soil surface even in mature plants.

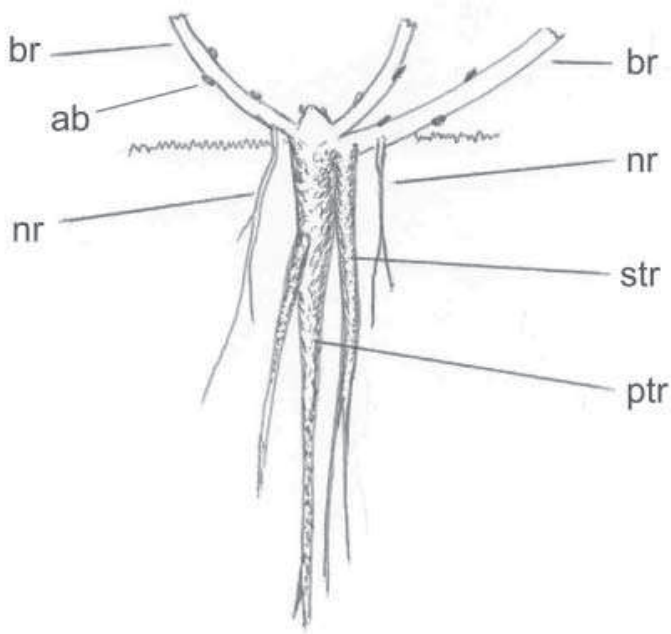

Figure 4 Diagram of an augmented crown. ab = axillary bud, $\mathrm{br}=$ branch, $\mathrm{nr}=$ nodal root, ptr $=$ primary (seminal) tap root, $\operatorname{str}=$ secondary tap root.

\section{The flowering phase}

In vegetative plants the cells in the axil at the base of the youngest developing leaf within a growing bud develop into a new bud capable only of growing out into a leafy branch. When shoots become reproductive, the cells in the axils of some newlyformed leaves within their terminal buds develop into flower head buds instead. In all cases, the extreme tips of the terminal buds on the flowering shoots remain vegetative. These flowering shoots elongate rapidly and grow strongly vertically in red and caucasian clovers, lotus and lucerne, and become totally committed to seed production. In these species, the axillary cells at all nodes in the uppermost regions of flowering shoots develop into flower heads instead of vegetative axillary buds. Total allocation of resources to developing seeds instead of to the shoots' growing tips results in cessation of terminal bud growth so that the flowering shoots become determinate in growth (Figure 5A). Flowering shoots of subterranean clover are similarly determinate but they remain horizontal. In white clover, however, the growth of stolons is indeterminate, and flower heads usually form only intermittently along a stolon. As a result, a pool of vegetative buds is interspersed between the flower heads and the terminal buds remain able to continue vegetative growth (Figure 5B).

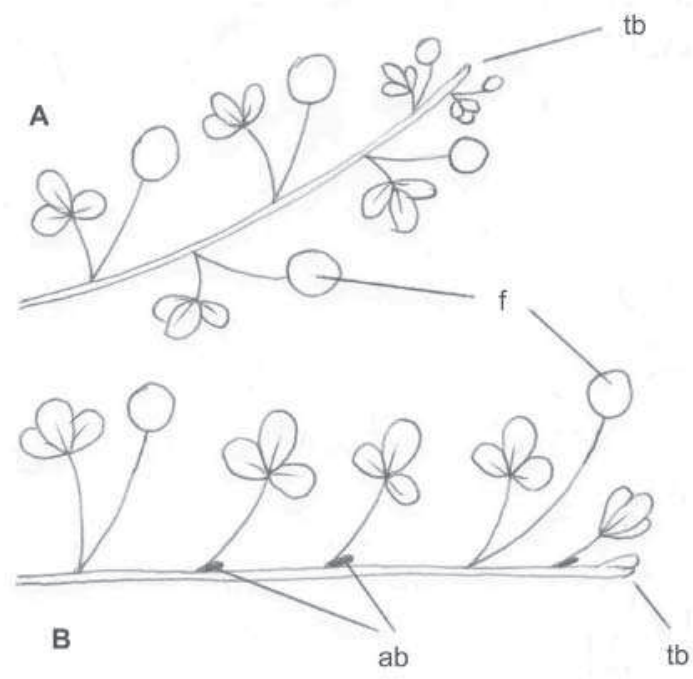

Figure 5 Diagrams showing the pattern of flower head development on $(A)$ determinate and $(B)$ indeterminate flowering shoots. $f$ $=$ flower head, $a b=$ (vegetative) axillary bud, tb = terminal bud.

\section{The post-flowering phase}

In perennial species with determinate flowering, all flowering shoots die back to near their bases after seed ripening, leaving a cluster of inactive buds close to ground level at the crown. With renewed growth in autumn and spring, many of these buds grow out into new shoots. In Lotus corniculatus, strong regrowth can occur from the lowermost buds remaining on the dead flowering shoots (stubble buds), but, in lucerne and red and caucasian clovers, very few of the basal buds on the flowering shoots remain viable after seed set, with the result that almost all of the regrowth takes place from buds lower on the crown. 


\section{Implications of morphological variation}

The implications of morphological variation can be understood by considering the extreme forms of white clover and lucerne. Each plant consists initially of a crown which produces multiple branches, at least for the first two or so years of its life. In white clover, however, branches grow horizontally as stolons (Figure 3D) whereas those of lucerne are erect (Figure $3 C$ ). As a result, the pool of vegetative buds is wholly at ground level in the former whereas in lucerne the bulk of buds is located above ground on the aerial shoots. Thus, lucerne is well adapted to compete for light in tall pasture but suffers a heavy loss of vegetative buds during grazing. In contrast, white clover competes poorly in tall pasture but loses relatively few buds during grazing. The pattern of flowering in each of these species has a strong impact on subsequent plant form (Figure 5). After determinate flowering in lucerne, the pool of buds is concentrated at the crown, whereas with indeterminate flowering in white clover it is widely dispersed.

\section{Nodal roots}

A key additional difference between these two growth forms lies in the ability to form nodal roots. In lucerne, carbon fixed by leaves during photosynthesis is only shared between growing shoots and the tap root system. This enables the seminal tap roots to continue growth over an extended period (Figure 6A), and thereby attain a depth of up to $6 \mathrm{~m}$. In white clover, however, the abundant outgrowth of nodal roots from stolons growing under moist conditions has a strong impact on the allocation of carbon and the subsequent form of the plant. In this species, carbon allocated to root growth is predominantly directed to the development of the nodal root systems along the stolons rather than to the basal root systems (Figure $6 \mathrm{~B})$. In a recent study comparing 10 -week-old vegetatively propagated plants, in which stolons were either prevented from forming any nodal roots or allowed to form a root system at each node, Thomas \& Hay (pers. comm.) found the dry weight of the basal roots to be $2.7 \mathrm{~g}$ in the former but only $1.1 \mathrm{~g}$ in the latter (in which the nodal roots weighed $3.8 \mathrm{~g}$ ). This direction of carbon away from the basal root system is likely to be a significant factor contributing to the death of the crown tap root and the stolon tissue basal to the oldest nodal roots after about two years (Brock et al. 2000). It is as a result of this death that the young plant subsequently splits into a number of clonal ramets.
When the development of nodal root systems is prevented, either by growing plants under dry conditions or in the mutant Mortal in which nodal rooting is suppressed (White et al. 1998) (Figure 6C), carbon allocation to the roots is directed totally to the crown tap root, which grows larger than in wildtype plants as a result. Thus, the development of both tap roots and nodal root systems on the same plant inevitably leads to compromise. Theoretically, maximal tap root development cannot be achieved in wild-type plants in the presence of nodal root systems. Plants of the mutant Mortal, however, are able to develop strong crown tap roots but are incapable of splitting into clonal ramets.

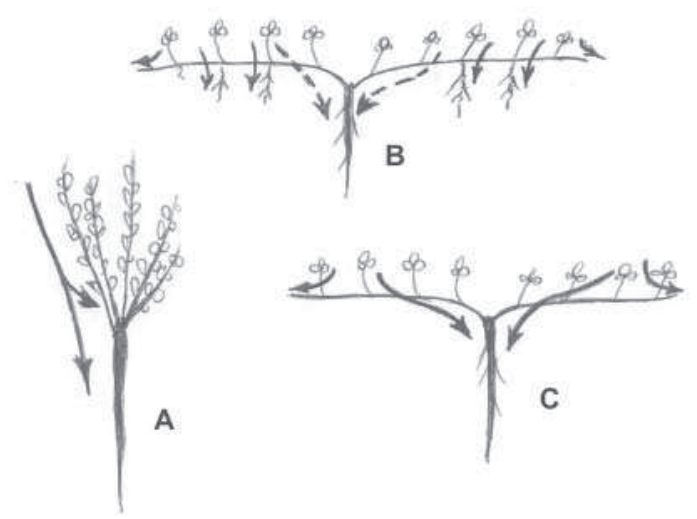

Figure 6 Diagrams showing patterns of carbon allocation (indicated by arrows) from leaves to roots in (A) lucerne, (B) white clover wild-type and $(C)$ the white clover mutant Mortal.

\section{Tap root longevity}

Under rich moist conditions, white clover tap roots rarely survive longer than two years (Brock et al. 2000), and those of red clover not more than 3 to 4 years. Roots of these species have a high proportion of soft parenchymatous tissue, and their early death is often ascribed to the invasion of this tissue by pathogens. Such tap root death is not necessarily the direct result of attack by pathogens, however; it must also be hastened by an inadequate supply of carbon from the leaves. Such a situation can occur when the carbon supply to basal roots of white clover is markedly reduced by the presence of nodal roots, as described in the previous section. This inverse relationship between nodal root formation and tap root growth and longevity is affirmed by observations of the longevity of red clover tap roots, the life of 


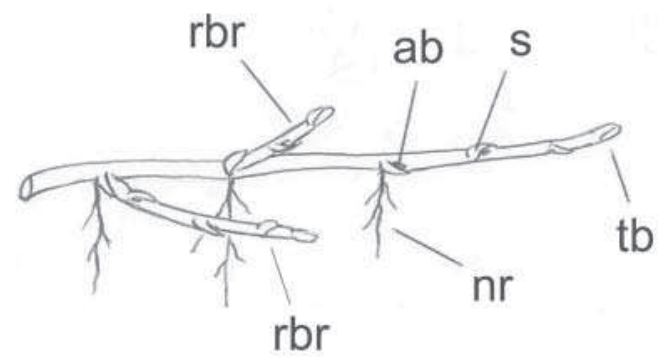

Figure 7 Diagram of a caucasian clover rhizome. $\mathrm{ab}=$ axillary bud, $\mathrm{s}=$ scale leaf, $\mathrm{tb}=$ terminal bud, $\mathrm{nr}=$ nodal root, $\mathrm{rbr}=$ branches growing as young rhizomes. which is increased to 5 years by growing plants in drier well-drained soil which leads to the production of fewer nodal roots (Taylor \& Quesenberry 1996).

\section{Further variations and the problem of caucasian clover}

The growth forms of red clover and lotus are similar to that of lucerne, but caucasian clover introduces an additional morphological feature. In this species, buds that form above ground in the light develop, as in the other species described, to produce photosynthetic foliage leaves, but those which grow into branches below the soil surface develop into rhizomes (Figure
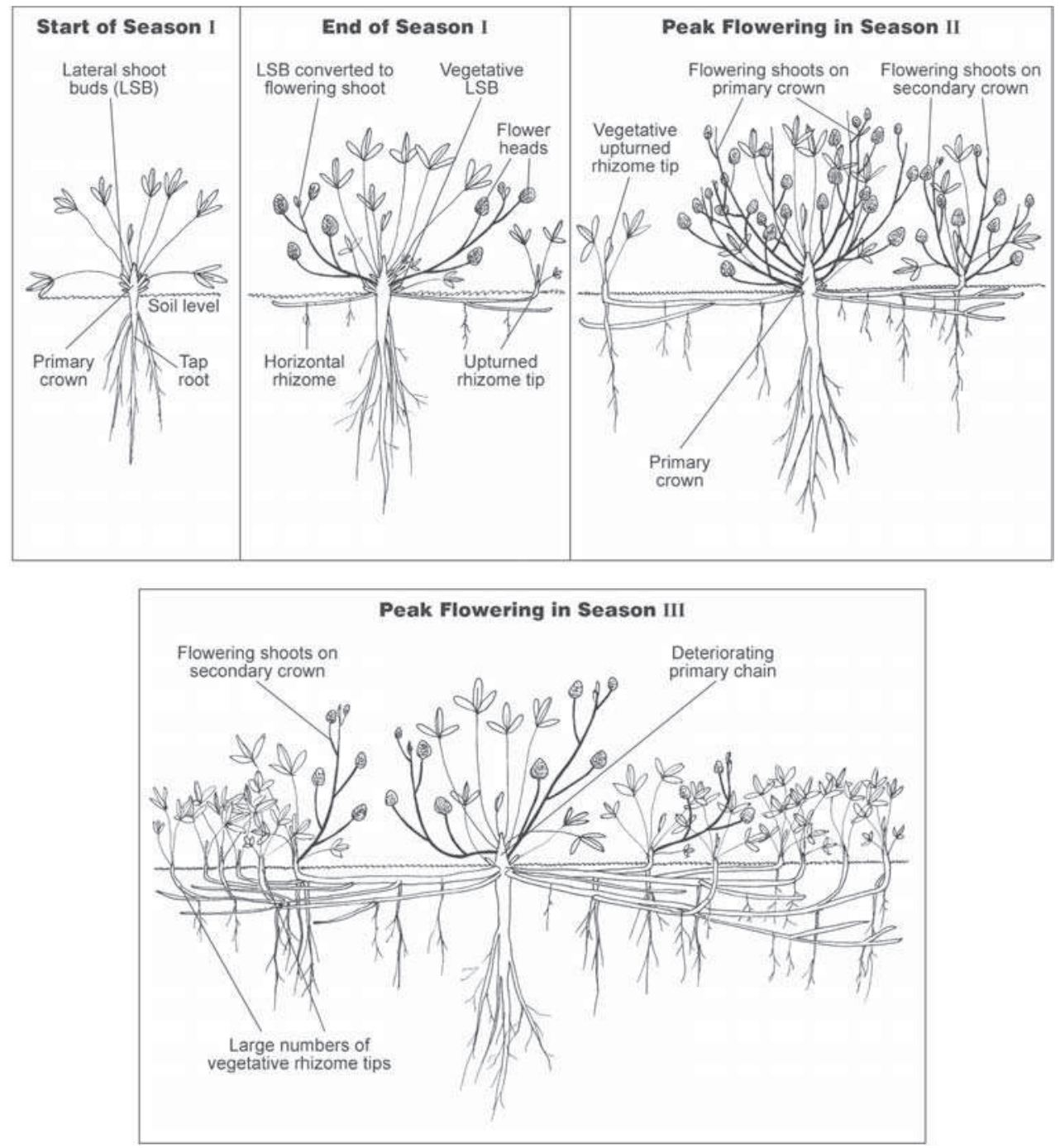

Figure 8 Diagrammatic representation of the growth of a caucasian clover plant during its first three and a half years. 
7). On these, the leaf primordia fail to grow into photosynthetic organs and develop instead into small colourless scale leaves 2 to $5 \mathrm{~mm}$ long. The development of rhizomes parallels that of aboveground stolons of white clover. Each scale leaf subtends an axillary bud capable of growing into a new rhizome branch and each node is capable of forming two nodal roots. Rhizome growth is at first totally dependent on carbon from the photosynthetic shoots, however, and clearly must compete with the growth of leafy shoots and roots for it. As a result, compared with white clover, in which nodal root systems are fed carbon by the foliage leaves at their nodes of origin, in the absence of associated foliage leaves in caucasian clover the nodal root systems develop relatively weakly. Eventually, after growing below ground for several centimetres, the tip of each rhizome branch stops elongating and grows upwards into the light where it forms a secondary crown and in many cases develops its own tap root (Figure 8).

\section{Carbon allocation patterns during seedling development}

\section{Early establishment}

The pattern of post-germination seedling growth is similar in all pasture legume species: the seminal root grows strongly into the soil utilising food reserves from the cotyledons and this is followed by the emergence of leaves on the primary stem (Figure 1). Subsequent growth of young leaves, buds and roots is then dependent on the translocation to them of carbon fixed during photosynthesis in the increasing number of leaves. Initially, the rate at which new leaves appear along the axis of the primary stem differs little between species. Black et al. (2002), for instance, found that five such leaves appeared during the first month of seedling growth at a mean temperature of $20^{\circ} \mathrm{C}$ in both white and caucasian clovers. The carbon allocation patterns in each differed greatly, however. By the time the first five leaves had appeared on the primary stems, axillary buds were beginning to grow out into branches in white clover, whereas caucasian seedlings still showed no sign of branch outgrowth. In caucasian clover, carbon was allocated equally to root growth and shoot production, leading to a root:shoot ratio of 0.50 . In comparison, for white clover the balance was weighted towards stolon production and the resultant root:shoot ratio was only 0.39 . Two different species-specific carbonallocation strategies are thus clearly in place right from the start of seedling development.

\section{Later establishment}

In the weeks following early establishment, the carbon-allocation strategies are maintained and the influence of different growth forms becomes more marked. In white clover, the allocation of carbon is biased towards shoot growth, and the development of nodal root systems on horizontal stolons under moist conditions provides additional sinks. This steers carbon allocation away from the tap root system at the crown (Figure 6B). In species with erect or semi-erect branches, in which the root system consists solely of a single tap root, all root-directed carbon is allocated to that root. Comparison of root development in 5-month-old white and caucasian clover seedlings in the field at Lincoln showed mean tap root lengths and widths halfway along their lengths to be $101 \pm 4.6 \mathrm{~mm}$ and $1.6 \pm 0.06 \mathrm{~mm}$, respectively, in white clover and $233 \pm 10.3 \mathrm{~mm}$ and $3.15 \pm 0.07 \mathrm{~mm}$ in caucasian (Thomas, unpublished).

Following this stage, at an age of 4 to 6 months, caucasian clover begins to produce underground rhizomes. From this time on, an even higher proportion of carbon is diverted away from aboveground shoot formation, inevitably slowing establishment. In 18-month-old plants, Widdup et al. (2003) found the ratios of total below-ground to aboveground tissues to be as high as 1.61 in caucasian clover compared with 0.23 in white clover. Caucasian clover plants cannot be considered to be fully established until they have developed a large number of secondary crowns.

\section{The dryland problem}

\section{Establishment}

Seedling establishment in environments that are subject to extended periods of water shortage is best when deep root systems are formed early. Theoretically, this requires a large leaf area to be produced rapidly in as much light as possible, with a high photosynthetic efficiency. This would maximise the fixation of carbon during photosynthesis in combination with the allocation of a very high proportion of that carbon to tap root development rather than to shoot growth. While lucerne and red clover fit these requirements quite well, caucasian clover's establishment is impeded by the diversion of carbon into rhizome development, and white clover's tap root development is weak.

\section{Persistence}

Under seasonally dry conditions, persistence requires 
the development of deeply penetrating long-lived tap roots that are able to reach whatever deep-seated soil moisture is available. Lucerne is well adapted in this respect, as is caucasian clover. The part played by rhizomes in contributing to persistence in the latter species is unclear.

The spreading form of white clover is highly successful in grazed pasture but is dependent on the development of shallow nodal root systems that are only produced under moist conditions. The better the conditions are for the development of nodal root systems, the more that are formed on a shoot and the smaller the share of carbon each has available for growth.

\section{A challenge: designing forage legumes for dryland environments}

From the preceding account, it is clear that there is a conflict between a plant's ability to maximise both leaf development and root development. Strong development of deeply penetrating roots must be at the expense of shoot production and vice versa. Thus, the form of every species is a compromise that can be envisaged as perhaps the best solution for the environment in which it evolved. This form might not be the best solution for the management systems employed agriculturally, though. Clearly there is scope for breeding forage legumes to suit specific management systems, but the prospects for developing the 'perfect' plant in each case is limited by the unavoidable trade-offs between root and shoot development; that is, between persistence and yield.

\section{REFERENCES}

Black, A.D.; Moot, D.J.; Lucas, R.J. 2002. Seedling development and growth of white clover, caucasian clover and perennial ryegrass grown in field and controlled environments. Proceedings of the New Zealand Grassland Association 64: 197-204.

Brock, J.L.; Albrecht, K.A.; Tilbrook, J.C.; Hay, M.J.M. 2000. Morphology of white clover during development from seed to clonal populations in grazed pastures. Journal of Agricultural Science 135: 103-111.

Forde, M.B.; Hay, M.J.M.; Brock, J.L. 1989.
Development and growth characteristics of temperate perennial legumes. pp. 91-110. In: Persistence of forage legumes. Eds. Marten, G.C.; Matches, A.G.; Barnes, R.F.; Brougham, R.W.; Clements, R.J.; Sheath, G.W. American Society of Agronomy, Inc.; Crop Science Society of America, Inc.; Soil Science Society of America, Inc. Madison, Wisconsin, USA.

Nelson, C.J.; Mosr, L.E. 1995. Morphology and systematics pp. 15-30. In: Forages. Volume 1: An introduction to grassland agriculture. Eds. Barnes, R.F.; Miller, D.A.; Nelson, C.J. Iowa State University Press, Ames, Iowa, USA.

Sheaffer, C.C. 1989. Effect of competition on legume persistence. pp. 327-334. In: Persistence of forage legumes. Eds. Marten, G.C.; Matches, A.G.; Barnes, R.F.; Brougham, R.W.; Clements, R.J.; Sheath, G.W. American Society of Agronomy, Inc.; Crop Science Society of America, Inc.; Soil Science Society of America, Inc. Madison, Wisconsin, USA.

Sheath, G.W.; Hay, R.J.M. 1989. Overview of legume persistence in New Zealand. pp. 23-36. In: Persistence of forage legumes. Eds. Marten, G.C.; Matches, A.G.; Barnes, R.F.; Brougham, R.W.; Clements, R.J.; Sheath, G.W. American Society of Agronomy, Inc.; Crop Science Society of America, Inc.; Soil Science Society of America, Inc. Madison, Wisconsin, USA.

Taylor, N.L.; Quesenberry, K.H. 1996. Red clover science. Kluwer Academic Publisher, Dordrecht. $226 \mathrm{pp}$.

Thomas, R.G.; Hay, M.J.M.; Newton, P.C.D. 2002. A developmentally based categorization of branching in Trifolium repens L.: influence of nodal roots. Annals of Botany 90: 379-389.

White, D.W.R.; Woodfield, D.R.; Caradus, J.R. 1998. Mortal: a mutant of white clover defective in nodal root development. Plant Physiology 116: 913-921.

Widdup, K.H.; Hussain, S.W.; Williams, W.M.; Lowther, W.L.; Pryor, H.N.; Sutherland, B.L. 2003. The development and plant characteristics of interspecific hybrids between Trifolium ambiguum and T. repens. In: Moot, D.J. (ed.) Legumes for dryland pastures. Proceedings of a New Zealand Grassland Association symposium, Lincoln University, 18-19 November 2003. Grassland Research and Practice Series; no. 11: 143-148. 
